\title{
Secondary oxidation product on Si(111)-(7×7) characterized by isotope-labeled vibrational spectroscopy
}

\section{$\operatorname{AUTHOR}(\mathrm{S})$ :}

Okuyama, H; Ohtsuka, Y; Aruga, T

\section{CITATION:}

Okuyama, H ...[et al]. Secondary oxidation product on Si(111)-(7x7) characterized by isotope-labeled vibrational spectroscopy. JOURNAL OF CHEMICAL PHYSICS 2005, 122(23): 234709.

\section{ISSUE DATE:}

2005-06-15

URL:

http://hdl.handle.net/2433/49833

\section{RIGHT:}

Copyright 2005 American Institute of Physics. This article may be downloaded for personal use only. Any other use requires prior permission of the author and the American Institute of Physics. 


\title{
Secondary oxidation product on $\mathrm{Si}(111)-(7 \times 7)$ characterized by isotope-labeled vibrational spectroscopy
}

\author{
H. Okuyama, ${ }^{\text {a) }}$ Y. Ohtsuka, and T. Aruga \\ Department of Chemistry, Graduate School of Science, Kyoto University, Kyoto 606-8502, Japan
}

(Received 17 February 2005; accepted 25 April 2005; published online 22 June 2005)

\begin{abstract}
The reaction of $\mathrm{O}_{2}$ with $\mathrm{Si}(111)-(7 \times 7)$ has been studied by electron energy-loss spectroscopy at $82 \mathrm{~K}$. In addition to the losses due to $\mathrm{Si}-\mathrm{O}-\mathrm{Si}$ configurations, we observed two $\mathrm{Si}-\mathrm{O}$ stretch modes depending on the coverage. A $146-\mathrm{meV}$ peak appears at the initial reaction stage and was ascribed to a metastable product with one oxygen atom bonding on top of Si adatom and the other inserted into the backbond. The initial product is further oxidized to produce the second $\mathrm{Si}-\mathrm{O}$ stretch peak at $150 \mathrm{meV}$. The secondary product was partially substituted with isotopes and analyzed with a simple model of coupled oscillators. The vibrational spectra reflect dynamical couplings between the isotopes, which is consistent with those predicted from the tetrahedral $\mathrm{SiO}_{4}$ structure with one on top and three inserted oxygen atoms. (C) 2005 American Institute of Physics.
\end{abstract}

[DOI: $10.1063 / 1.1937394]$

\section{INTRODUCTION}

As a consequence of device miniaturization, silicon oxide will be scaled down to thickness of only a few atomic layers. ${ }^{1}$ Initial oxidation of silicon surfaces has been studied for the atomic-scale understanding of the oxide formation process. Over the last three decades, the reaction of $\mathrm{O}_{2}$ gas with $\mathrm{Si}(111)-(7 \times 7)$ has been studied by many researchers from both experimental ${ }^{2-22}$ and theoretical ${ }^{23-28}$ points of view. A controversy arised from an equivocal assignment of the metastable $150-\mathrm{meV}$ vibrational peak observed by electron energy-loss spectroscopy (EELS). The $150-\mathrm{meV}$ peak was initially assigned to the internal mode of molecular species, ${ }^{2,3}$ which was supported by photoemission ${ }^{4}$ and work-function measurement. ${ }^{6}$

On the other hand, Schell-Sorokin and Demuth ${ }^{5}$ proposed assigning the peak to the diatomiclike silicon monoxide ( $\mathrm{SiO}$ species). By employing density-functional theory, Lee and Kang ${ }^{25}$ suggested that the $150-\mathrm{meV}$ vibrational peak is indeed attributable to the $\mathrm{Si}-\mathrm{O}$ stretch mode. They proposed that the ad-ins structure [Fig. 1(a)] is thermally metastable and is a candidate for an initial product at low temperature. The notations "ad" and "ins" represent an oxygen atom bonded on top of $\mathrm{Si}$ adatom and that inserted into a backbond, respectively. The absence of molecular state was supported by reactive $\mathrm{Cs}^{+}$ion scattering experiment, which detected no $\mathrm{CsSiO}_{2}{ }^{+}$or $\mathrm{CsO}_{2}{ }^{+}$as a scattering product. ${ }^{11}$ Comtet et al. observed $\mathrm{O}^{+}$ion as a photodesorption product, ${ }^{15}$ which was attributed to the on-top $\mathrm{SiO}$ species based on the comparative analysis with electron photoemission spectra. The recent EELS study provided spectroscopic evidence that the initial reaction results in the ad-ins structure at $82 \mathrm{~K}^{20}$

It was proposed that the metastable ad-ins structure transforms into ins $\times 2$ structure [Fig. 1(b)] by thermal

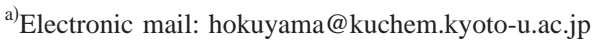

activation. ${ }^{15,19,20,25}$ The ad-ins and ins $\times 2$ products were imaged by scanning tunneling microscope (STM) at $78 \mathrm{~K}$ (Refs. 17, 20, and 22) and $30 \mathrm{~K},{ }^{19}$ which appears dark and bright at the adatom sites, respectively, in agreement with the theoretical predictions. ${ }^{24,25}$ Thus, by recent studies of both theories and experiments, it is now a consensus that the initial oxidation product on $\mathrm{Si}(111)-(7 \times 7)$ is the ad-ins-type at $\sim 80 \mathrm{~K}$ which converts to the stable ins $\times 2$ structure at higher temperature [200 K (Ref. 20)].

The initial products are further oxidized with increasing the exposure, although the structure remains controversial. Several photoemission studies proposed that the molecular configuration is possible as a secondary product at $\sim 100 \mathrm{~K}$ (Refs. 12, 16, and 18) and $300 \mathrm{~K},{ }^{14,18,21}$ and that the structure is stabilized against the dissociation by the inserted oxygen atom. Although the temperature reported was different, the x-ray-absorption study showed distinct molecular feature only below $200 \mathrm{~K} .^{13}$ The molecular configuration, however, was not consistent with the theories, which proposed that it spontaneously dissociates, yielding a tetrahedral $\mathrm{SiO}_{4}$ structure denoted by ad-ins $\times 3$ [Fig. 1(c)]. ${ }^{23,26}$ Comtet et al. ${ }^{15}$ supported the $\mathrm{SiO}_{4}$ structure by analyses of $\mathrm{O}^{+}$photodesorption yield as a function of temperature, coverage, and photon energy. The photodesorption yield showed resonances at the same energies as those observed for silicon oxide, which suggested the tetrahedral atomic arrangement of oxygen atoms. The discrepancy was suggested to arise from the ambiguity in the assignment of the photoemission peak to the specific configuration of the product. ${ }^{29}$ In this study, we studied the secondary product by means of isotope-labeled vibrational spectroscopy at $82 \mathrm{~K}$. The secondary product was partially substituted with the isotope and the vibrational spectra were analyzed with the model of coupled oscillators, which enabled us to convincingly assign the secondary product as the ad-ins $\times 3$ structure. 


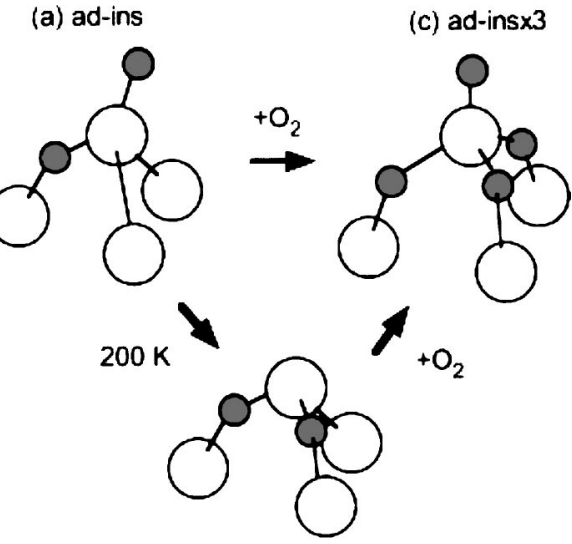

(b) ins $\times 2$

FIG. 1. Schematic model of oxidation reaction on $\mathrm{Si}(111)-(7 \times 7)$. The open and gray circles indicate the $\mathrm{Si}$ and $\mathrm{O}$ atoms, respectively. The initial product at $82 \mathrm{~K}$ is of the ad-ins type which transforms to the ins $\times 2$ structure at $200 \mathrm{~K}$. It was proposed that the successive reaction with further $\mathrm{O}_{2}$ produces the ad-ins $\times 3$ structure (Refs. 23 and 26).

\section{EXPERIMENTS}

The experiments were carried out in an ultrahighvacuum (UHV) chamber equipped with a high-resolution electron energy-loss spectrometer (LK-5000, LK Technologies, Inc.) and a four-grid retarding-field analyzer for lowenergy electron diffraction (LEED). The base pressure of the chamber was below $1 \times 10^{-10}$ Torr. For the EELS measurements, the incidence angle $\theta_{i}=60^{\circ}$, reflection angle $\theta_{r}=60^{\circ}$, and energy resolution of 3-4 meV (the full width at half maximum of the elastic peak) were used. The scattering plane was aligned along the $[01 \overline{1}]$ direction. The angledependent measurements revealed that the dipole scattering is responsible for the observed losses. ${ }^{30}$

The silicon used in the experiments was cut from an $n$-type, As-doped wafer, which was cleaned by the overnight degassing at $900 \mathrm{~K}$, followed by the flashing up to $1500 \mathrm{~K}$. For a clean surface, a sharp $(7 \times 7)$ LEED pattern was observed and EELS showed no trace of impurity. We used isotope gasses of ${ }^{16} \mathrm{O}_{2}$ and ${ }^{18} \mathrm{O}_{2}$ with the purities of $99.9 \%$ and $99 \%$, respectively. The sample was exposed to ${ }^{16} \mathrm{O}_{2}$ and/or ${ }^{18} \mathrm{O}_{2}$ via two different tube dosers which were positioned $\sim 1 \mathrm{~cm}$ apart from the sample surface. Exposures are given by background $\mathrm{O}_{2}$ pressure multiplied by time in units of langmuir $\left(1 \mathrm{~L}=1 \times 10^{-6}\right.$ Torr $\left.\mathrm{s}\right)$. The actual exposure was larger than indicated due to the use of dosers by a factor of $\sim 7$. The exposure and EELS measurements were conducted at $82 \mathrm{~K}$.

\section{RESULTS AND DISCUSSION}

A series of EELS spectra of ${ }^{16} \mathrm{O}_{2} / \mathrm{Si}(111)-(7 \times 7)$ are shown in Fig. 2 as a function of the exposure. At the initialstage reaction, two peaks appear at 80 and $146 \mathrm{meV}$ [(b) and (c)]. As the exposure increases to $0.03 \mathrm{~L}$, two peaks start to develop at 128 and $150 \mathrm{meV}$ (d). It was already established that the $80-$ and $128-\mathrm{meV}$ losses are ascribed to the $\mathrm{Si}-\mathrm{O}-\mathrm{Si}$ symmetric and asymmetric stretch modes, respectively. ${ }^{2}$ The 146- and $150-\mathrm{meV}$ peaks, denoted by $\nu_{1}$ and $\nu_{2}$, respectively, were assigned to the $\mathrm{Si}-\mathrm{O}$ stretch modes. ${ }^{20}$ The initial fea-

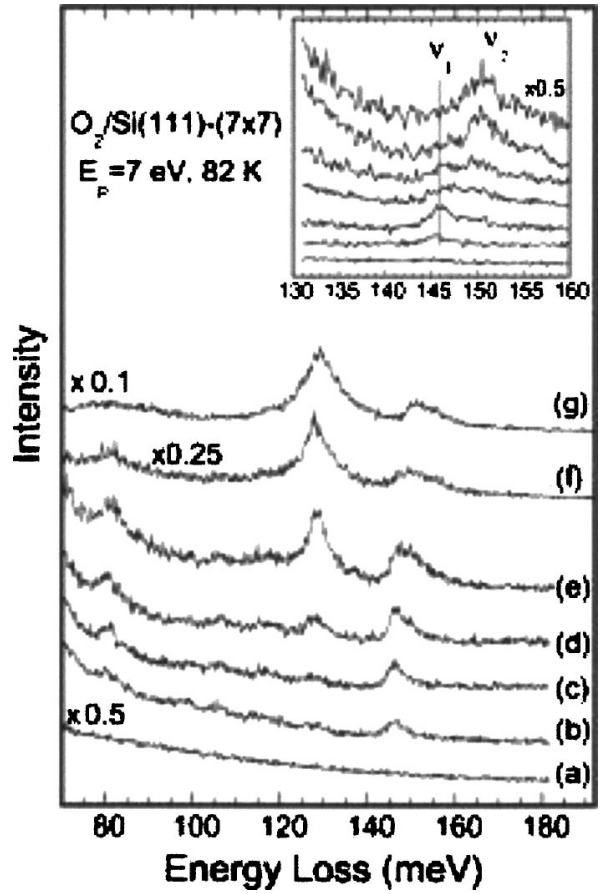

FIG. 2. EELS spectra of $\mathrm{Si}(111)-(7 \times 7)$ as a function of the exposure to ${ }^{16} \mathrm{O}_{2}$ taken at $E_{p}=7 \mathrm{eV}$. The exposures are (a) 0 , (b) 0.01 , (c) 0.02 , (d) 0.03 , (e) 0.07 , (f) 0.1 , and (g) $0.2 \mathrm{~L}$. The inset shows the inspect of the $\mathrm{Si}-\mathrm{O}$ stretch region taken with another sample at $E_{p}=8 \mathrm{eV}$. The exposures are $0.01,0.02,0.04,0.06,0.08,0.1$, and $0.15 \mathrm{~L}$ from the bottom to the top. The loss intensities are normalized to the elastic peak intensities.

tures at 80 and $146 \mathrm{meV}$ were assigned to the $\mathrm{Si}-\mathrm{O}-\mathrm{Si}$ and $\mathrm{Si}-\mathrm{O}$ stretch modes, respectively, of the ad-ins structure. ${ }^{20}$ The exposure dependences of the $\nu_{1}$ and $\nu_{2}$ peaks are shown in the inset. The $\nu_{1}$ peak grows at first and then attenuates in intensity, accompanied with the growth of the $\nu_{2}$ peak. This result suggests that the initial product is further oxidized to yield the secondary product. The secondary product is characterized by $\nu_{2}$ and two $\mathrm{Si}-\mathrm{O}-\mathrm{Si}$ stretch modes at 80 and $128 \mathrm{meV}$. At $0.1-0.2 \mathrm{~L}$, the $128-\mathrm{meV}$ peak is broadened and shifts to $129 \mathrm{meV}$. Also a broad structure is observed around $70-100 \mathrm{meV}$, indicating that the surface is inhomogeneous with various $\mathrm{Si}-\mathrm{O}-\mathrm{Si}$ configurations.

The temperature effect of the initial product is shown in Fig. 3. The clean surface was exposed to $0.02-\mathrm{L}{ }^{16} \mathrm{O}_{2}$ at $82 \mathrm{~K}$, and two peaks appear at 80 and $146 \mathrm{meV}$ due to the initial product [spectrum (a)]. The sample was subsequently annealed to $200 \mathrm{~K}$ and then cooled to $82 \mathrm{~K}$ [spectrum (b)]. The $\nu_{1}$ peak disappears and two losses are observed at 81 and $104 \mathrm{meV}$. Spectrum $\left(\mathrm{b}^{\prime}\right)$ was taken after a similar sample preparation except for the use of the ${ }^{18} \mathrm{O}_{2}$ isotope, which exhibits losses at 80 and $100 \mathrm{meV}$. Although the signal-to-noise ratio is not sufficiently high, the isotope shifts ensure that these two peaks are derived from oxygen. The disappearance of the $\nu_{1}$ peak suggests that the metastable on-top oxygen migrates into the backbond to form the ins $\times 2$ structure by thermal activation. ${ }^{25}$ For the ins $\times 2$ structure, it is anticipated that the two inserted oxygen atoms are dynamically coupled and the $\mathrm{Si}-\mathrm{O}-\mathrm{Si}$ symmetric and asymmetric stretch modes are further classified by in-phase and out-of-phase motions. The theory predicted the vibrational energies of the in-phase symmetric and asymmetric stretch 


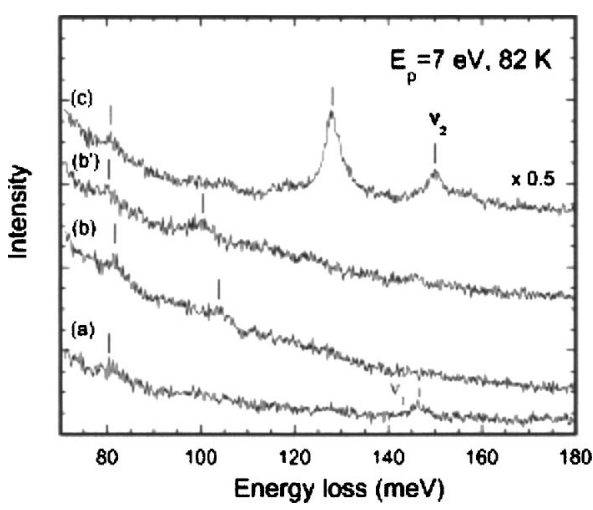

FIG. 3. (a) An EELS spectrum of $\mathrm{Si}(111)-(7 \times 7)$ exposed to $0.02-\mathrm{L}^{16} \mathrm{O}_{2}$ at $82 \mathrm{~K}$. The 80 - and 146-meV losses are characteristic of the ad-ins product. (b) The surface was subsequently heated to $200 \mathrm{~K}$. The $\nu_{1}$ peak disappears and two peaks are observed at 81 and $104 \mathrm{meV}$, which are ascribed to the ins $\times 2$ product. $\left(b^{\prime}\right)$ The corresponding spectrum taken with ${ }^{18} \mathrm{O}_{2}$, which exhibits isotope-shifted peaks at 80 and $100 \mathrm{meV}$. (c) The surface after annealing [spectrum (b)] was further exposed to $0.02-\mathrm{L}{ }^{16} \mathrm{O}_{2}$. The 80-, 128-, and $150-\mathrm{meV}$ peaks are characteristic of the secondary product.

modes to be 78 and $97 \mathrm{meV}$, respectively. ${ }^{26} \mathrm{We}$ assign the 81(80)- and 104(100)-meV peaks to the in-phase symmetric and asymmetric stretch modes, respectively. The out-ofphase modes are forbidden according to the surface selection rule of dipole scattering. ${ }^{30}$ The experimental energies for the initial and secondary products are summarized in Table I.

The secondary product results from subsequent oxidation of the ad-ins product as shown in Fig. 2. The $\nu_{1}$ peak disappears and the $\nu_{2}$ peak becomes dominant at $0.1 \mathrm{~L}$, where the $\mathrm{Si}-\mathrm{O}-\mathrm{Si}$ stretch peaks are significantly broadened due to the surface inhomogeneity. We found that the secondary species can be readily produced via the ins $\times 2$ structure. The surface after annealing [spectrum (b) in Fig. 3] was further exposed to $0.02-\mathrm{L}{ }^{16} \mathrm{O}_{2}$ at $82 \mathrm{~K}$ (total exposure is $0.04 \mathrm{~L})$ [spectrum (c)]. The $\nu_{2}$ peak appears predominantly in the $\mathrm{Si}-\mathrm{O}$ stretch region without significant contribution of the $\nu_{1}$ peak. Furthermore, the $\mathrm{Si}-\mathrm{O}-\mathrm{Si}$ asymmetric stretch peak at $128 \mathrm{meV}$ is relatively sharp, indicating higher homogeneity of the product. Although there may exist unreacted ins $\times 2$ species, it gives no vibrational feature at $120-150 \mathrm{meV}$. These results suggest that the postexposed oxygen reacts preferentially with the ins $\times 2$ species: The ins $\times 2$ species is more reactive to incoming $\mathrm{O}_{2}$ than the adins species and possibly even unreacted $\mathrm{Si}$ adatoms. The high reactivity of the ins $\times 2$ species is corroborated by the STM

TABLE I. A summary of experimental energies (meV) with ${ }^{16} \mathrm{O}_{2}\left({ }^{18} \mathrm{O}_{2}\right)$ and mode assignments for the structures shown in Fig. 1.

\begin{tabular}{ccc}
\hline \hline Structure & Energy $(\mathrm{meV})$ & Assignment \\
\hline ad-ins & $80(78)$ & $\mathrm{Si}-\mathrm{O}-\mathrm{Si}$ stretch $(\mathrm{s})$ \\
$\ldots$ & $146(142)$ & $\mathrm{Si}-\mathrm{O}$ stretch, $\nu_{1}$ \\
ins $\times 2$ & $81(80)$ & $\mathrm{Si}-\mathrm{O}-\mathrm{Si}$ stretch $(\mathrm{s})$ \\
$\ldots$ & $104(100)$ & $\mathrm{Si}-\mathrm{O}-\mathrm{Si}$ stretch (as) \\
ad-ins $\times 3$ & $80(78)$ & $\mathrm{Si}-\mathrm{O}-\mathrm{Si}$ stretch (s) \\
$\ldots$ & $128-129(122-123)$ & $\mathrm{Si}-\mathrm{O}-\mathrm{Si}$ stretch $($ as $)$ \\
$\ldots$ & $150(145)$ & $\mathrm{Si}-\mathrm{O}$ stretch, $\nu_{2}$ \\
\hline \hline
\end{tabular}

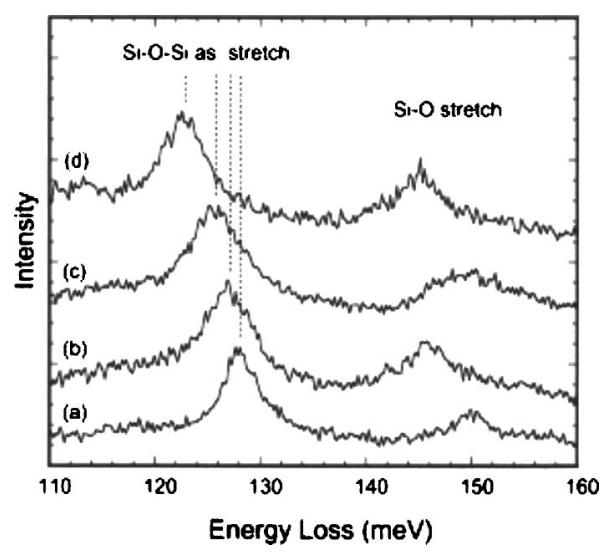

FIG. 4. Isotope-labeled EELS spectra of the secondary oxidation products prepared by way of the two-step reaction: The clean surface was exposed to $0.02-\mathrm{L}^{16} \mathrm{O}_{2}[(\mathrm{a})$ and (b) $]$ or ${ }^{18} \mathrm{O}_{2}[(\mathrm{c})$ and (d)], and subsequently heated to $200 \mathrm{~K}$. Then the surface was further exposed to $0.02-\mathrm{L}^{16} \mathrm{O}_{2}[(\mathrm{a})$ and (c) $]$ or ${ }^{18} \mathrm{O}_{2}[(\mathrm{~b})$ and (d)]. The $\mathrm{Si}-\mathrm{O}$ stretch mode is associated with the postexposed isotope. The $\mathrm{Si}-\mathrm{O}-\mathrm{Si}$ asymmetric stretch modes show energy shifts depending on the isotopic combinations due to dynamical couplings.

observation that a bright site (ins $\times 2$ ) is reactive toward the incoming $\mathrm{O}_{2}$ to produce a dark site (secondary product). ${ }^{7,9}$

The secondary product is characterized by one $\mathrm{Si}-\mathrm{O}$ stretch mode $\left(\nu_{2}\right)$ and two $\mathrm{Si}-\mathrm{O}-\mathrm{Si}$ stretch modes at 80 and $128 \mathrm{meV}$. The exposure dependence of the $\nu_{1}$ and $\nu_{2}$ peaks (Fig. 2) suggests that the secondary product is the ad-ins $\times 3$ type. Then the $80-$ and $128-\mathrm{meV}$ peaks are assigned to the $\mathrm{Si}-\mathrm{O}-\mathrm{Si}$ symmetric and asymmetric stretch modes of the three inserted oxygen. To make a clearer assignment, the secondary product was partially substituted with oxygen isotope by way of the two-step reaction demonstrated in Fig. 3. For example, the clean $\mathrm{Si}(111)-(7 \times 7)$ surface was exposed to $0.02-\mathrm{L}{ }^{16} \mathrm{O}_{2}$ and subsequently heated to $200 \mathrm{~K}$, which yields only ins ${ }^{16} \times 2$ species on the surface. The surface was subsequently exposed to $0.02-\mathrm{L}{ }^{18} \mathrm{O}_{2}$ at $82 \mathrm{~K}$ to produce the secondary species. In this way, we prepared the surface with four different procedures as ${ }^{16} \mathrm{O}_{2} \rightarrow 200 \mathrm{~K} \rightarrow{ }^{16} \mathrm{O}_{2},{ }^{16} \mathrm{O}_{2}$ $\rightarrow 200 \mathrm{~K} \rightarrow{ }^{18} \mathrm{O}_{2},{ }^{18} \mathrm{O}_{2} \rightarrow 200 \mathrm{~K} \rightarrow{ }^{16} \mathrm{O}_{2}$, and ${ }^{18} \mathrm{O}_{2} \rightarrow 200 \mathrm{~K}$ $\rightarrow{ }^{18} \mathrm{O}_{2}$. The corresponding EELS spectra are shown in Fig. 4. For the secondary product constituted with only ${ }^{16} \mathrm{O}$, the $\mathrm{Si}-\mathrm{O}-\mathrm{Si}$ asymmetric and $\mathrm{Si}-\mathrm{O}$ stretch modes are observed at $128.1 \pm 0.2$ and $150 \mathrm{meV}$, respectively [spectrum (a)]. When completely substituted with ${ }^{18} \mathrm{O}$, the secondary product shows corresponding downshifted peaks at $122.8 \pm 0.2$ and $145 \mathrm{meV}$. In the case of partial substitutions, the $\mathrm{Si}-\mathrm{O}$ stretch modes are observed at 146 and $150 \mathrm{meV}$ for (b) and (c), respectively, indicating that the postexposed oxygen dissociates and one bonds on top of Si adatom. Furthermore, the $\mathrm{Si}-\mathrm{O}-\mathrm{Si}$ asymmetric stretch modes appear at $127.1 \pm 0.2$ and $125.7 \pm 0.2 \mathrm{meV}$ for (b) and (c), respectively, which lie in the intermediate of (a) and (d). The result indicates that this mode is associated with both pre- and postexposed isotopes; the dissociated counterpart of the postexposed isotope is inserted into the intact backbond. The multiply inserted oxygen atoms causes dynamical coupling of the $\mathrm{Si}-\mathrm{O}-\mathrm{Si}$ stretch vibration, giving rise to different normal modes depending on the isotopic combinations. Thus the spectra are quite consistent with the assignment that the secondary product is of the ad-ins $\times 3$ type. 
To make a quantitative analysis of the vibrational spectra, three coupled oscillators are considered as a model of the $\mathrm{Si}-\mathrm{O}-\mathrm{Si}$ asymmetric stretch vibrations of the ad-ins $\times 3$ structure. Within the harmonic approximation, the Hamiltonian is represented by

$$
H=\sum_{i=1}^{3} \epsilon_{i} c_{i}^{\dagger} c_{i}+\sum_{i, j=1}^{3} \Delta_{i, j} c_{i}^{\dagger} c_{j} .
$$

The notations of the Hubbard model are used for simple description of the matrix elements, where $c_{i}^{\dagger}\left(c_{i}\right)$ is the creation (annihilation) operator for the site (oscillator) $i . \epsilon_{i}$ is the vibrational energy of oscillator $i$ without dynamical couplings, and $\Delta_{i, j}$ corresponds to the dynamical interaction be- tween them. We consider $\epsilon_{16}$ and $\epsilon_{18}$ for $\mathrm{Si}-{ }^{16} \mathrm{O}-\mathrm{Si}$ and $\mathrm{Si}-{ }^{18} \mathrm{O}-\mathrm{Si}$ oscillators, respectively, and interaction parameters $\Delta_{16,16}, \Delta_{16,18}$, and $\Delta_{18,18}$ between them.

We treat the interactions perturbatively and start with the local oscillator basis as verified from $\epsilon \gg \Delta$. In the case of $\mathrm{ad}^{18}$-ins ${ }^{16} \times 2$-ins ${ }^{18}$ structure, for example, the Hamiltonian is represented by

$$
H=\left(\begin{array}{ccc}
\epsilon_{16} & \Delta_{16,16} & \Delta_{16,18} \\
\Delta_{16,16} & \epsilon_{16} & \Delta_{16,18} \\
\Delta_{16,18} & \Delta_{16,18} & \epsilon_{18}
\end{array}\right) .
$$

The matrix can be diagonalized analytically to yield the eigenvalues,

$$
\begin{aligned}
& E_{1,2}=\frac{\epsilon_{16}+\epsilon_{18}+\Delta_{16,16} \pm \sqrt{\epsilon_{16}^{2}+\epsilon_{18}^{2}-2 \epsilon_{16} \epsilon_{18}+2 \epsilon_{16} \Delta_{16,16}-2 \epsilon_{18} \Delta_{16,16}+\Delta_{16,16}^{2}+8 \Delta_{16,18}^{2}}}{2}, \\
& E_{3}=\epsilon_{16}-\Delta_{16,16} .
\end{aligned}
$$

In a similar way, the eigenvalues were deduced for the other combinations. Among the two or three normal modes for each combination, we consider only totally symmetric modes according to the surface selection rule of dipole scattering. In the above case, two totally symmetric modes appear which are classified as in-phase $\left(E_{1}\right)$ and out-of-phase $\left(E_{2}\right)$ motions. As described below, the EELS intensities for the out-of-phase modes are weak compared to those of the in-phase modes. Thus we fitted the experimental energies to those for the in-phase modes by the method of least square, and determined the parameters to be $124.1 \pm 0.2,119.1 \pm 0.2$, and $2.0 \pm 0.1 \mathrm{meV}$ for $\epsilon_{16}, \epsilon_{18}$, and $\Delta$, respectively. Here, we put $\Delta_{16,16}=\Delta$, and approximately $\Delta_{16,18}=\sqrt{\frac{17}{18}} \Delta$ and $\Delta_{18,18}$ $=\sqrt{\frac{16}{18}} \Delta$. The results are presented in Table II and Fig. 5 as a function of $\Delta$. The solid and dashed curves indicate the inphase and out-of-phase modes, respectively. The experimental energies are plotted by the dots, which are well reproduced by the model.

In the cases of partial substitutions, the out-of-phase modes are predicted to appear at 118.2 and $119.5 \mathrm{meV}$ (dashed curves) for the ins ${ }^{16} \times 2$-ins ${ }^{18}$ and ins ${ }^{16}$-ins ${ }^{18} \times 2$ combinations, respectively. The EELS intensity is propor-

TABLE II. Energies of the Si-O-Si asymmetric stretch modes observed in the isotope-labeled experiments and the results of the least-squares fitting $(\mathrm{meV})$. The procedure ${ }^{16} \mathrm{O}_{2}+{ }^{18} \mathrm{O}_{2}$ indicates that the clean surface was exposed to ${ }^{16} \mathrm{O}_{2}$, heated to $200 \mathrm{~K}$, and subsequently exposed to ${ }^{18} \mathrm{O}_{2}$.

\begin{tabular}{ccc}
\hline \hline Procedure & Expt. & Fit \\
\hline${ }^{16} \mathrm{O}_{2}+{ }^{16} \mathrm{O}_{2}$ & $128.1 \pm 0.2$ & 128.1 \\
${ }^{16} \mathrm{O}_{2}+{ }^{18} \mathrm{O}_{2}$ & $127.1 \pm 0.2$ & 127.0 \\
${ }^{18} \mathrm{O}_{2}+{ }^{16} \mathrm{O}_{2}$ & $125.7 \pm 0.2$ & 125.7 \\
${ }^{18} \mathrm{O}_{2}+{ }^{18} \mathrm{O}_{2}$ & $122.8 \pm 0.2$ & 122.9 \\
\hline \hline
\end{tabular}

tional to the square of the dynamic dipole moment induced by the excitations. The relative dipole moments can be derived from the calculated eigenvectors, which are schematically shown in Fig. 6. The normal components of the total dipole moments are larger for the in-phase mode than the out-of-phase mode by a factor of 3.3 and 2.2 for the ins ${ }^{18}$-ins ${ }^{16} \times 2$ and ins $^{16}{ }^{\text {-ins }}{ }^{18} \times 2$ configurations, respectively. Thus the corresponding intensity ratios are $\sim 11$ and $\sim 5$ for the former and latter, respectively, indicating that the out-of-phase counterparts are almost invisible in the spectra.

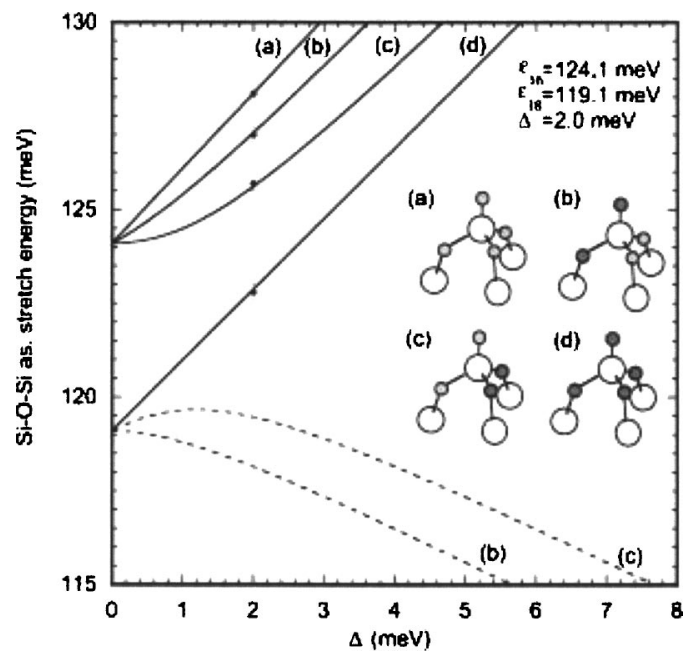

FIG. 5. The calculated energies of the $\mathrm{Si}-\mathrm{O}-\mathrm{Si}$ asymmetric stretch modes as a function of the interaction parameter $\Delta$. The isotopic combinations are (a) ins ${ }^{16} \times 3$, (b) ins ${ }^{18}$-ins ${ }^{16} \times 2$, (c) ins ${ }^{16}$-ins ${ }^{18} \times 2$, and (d) ins ${ }^{18} \times 3$. The schematic structures are depicted in the inset, where the open, gray, and black circles indicate $\mathrm{Si},{ }^{16} \mathrm{O}$, and ${ }^{18} \mathrm{O}$ atoms, respectively. The solid and dashed curves correspond to the in-phase and out-of-phase modes, respectively. For (a) and (d), the out-of-phase modes are dipole forbidden and thus are not presented. The experimental energies are shown by the dots, and the parameters $\epsilon_{16}, \epsilon_{18}$, and $\Delta$ were determined by the least-squares fitting. 

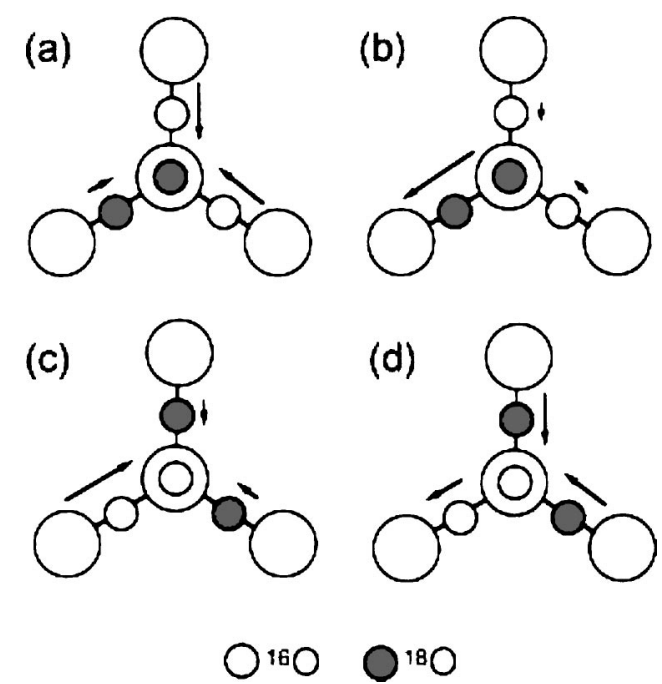

FIG. 6. Schematic of the $\mathrm{Si}-\mathrm{O}-\mathrm{Si}$ asymmetric stretch vibrations of the $[(\mathrm{a})$ and (b) $] \mathrm{ad}^{18}{ }^{1}$-ins ${ }^{18}$-ins ${ }^{16} \times 2$ and $[(\mathrm{c})$ and (d) $] \mathrm{ad}^{16}{ }^{16}$-ins ${ }^{16}$-ins ${ }^{18} \times 2$ structures. The large open circles indicate $\mathrm{Si}$ atoms, and the small gray and black circles indicate ${ }^{16} \mathrm{O}$ and ${ }^{18} \mathrm{O}$ atoms, respectively. The normal modes are represented by the [(a) and (c)] in-phase and [(b) and (d)] out-of-phase motions of the oxygen atoms. The arrows are depicted with its length proportional to the dynamic dipole moment induced by the excitations.

It is noted that the $\mathrm{Si}$ adatom belongs to the $C_{s}$ point group (slightly distorted from $C_{3 V}$ due to the surface reconstruction). The distortion may cause inhomogeneous broadening of the vibrational peaks in the case of partial substitutions. However, no significant broadenings were observed as compared to the spectra for the pure isotopes, verifying that the distortion is negligible and three inserted oxygen can be treated almost equivalently in the calculation of the normal modes. As a whole, the vibrational energies of the isotopelabeled experiments are well reproduced by the model of three coupled oscillators, which enabled us to unequivocally assign the secondary product as the ad-ins $\times 3$ structure.

\section{SUMMARY}

The secondary oxidation product on $\mathrm{Si}(111)-(7 \times 7)$ was investigated at $82 \mathrm{~K}$ by isotope-labeled EELS. The $\mathrm{Si}-\mathrm{O}-\mathrm{Si}$ asymmetric stretch mode was analyzed with partial isotopic substitution. The vibrational spectra can be explained by considering dynamical couplings between three inserted oxygen atoms, and thus, the secondary product was convincingly assigned as the ad-ins $\times 3$ structure. The result further indicates that the reaction scheme shown in Fig. 1 is established as an initial oxidation process of $\mathrm{Si}(111)-(7 \times 7)$.

\section{ACKNOWLEDGMENT}

This work was supported in part by a Grant-in-Aid from the Ministry of Education, Science, Sports and Culture (Japan).

${ }^{1}$ J. Dąbrowski and H.-J. Müssig, Silicon Surfaces and Formation of Interfaces (World Scientific, Singapore, 1999).

${ }^{2}$ H. Ibach, H. D. Bruchmann, and H. Wagner, Appl. Phys. A: Solids Surf. 29, 113 (1982).

${ }^{3}$ K. Edamoto, Y. Kubota, H. Kobayashi, M. Onchi, and M. Nishijima, J. Chem. Phys. 83, 428 (1985).

${ }^{4}$ U. Höfer, P. Morgen, W. Wurth, and E. Umbach, Phys. Rev. Lett. 55, 2979 (1985).

${ }^{5}$ A. J. Schell-Sorokin and J. E. Demuth, Surf. Sci. 157, 273 (1985).

${ }^{6}$ C. Silvestre and M. Shayegan, Phys. Rev. B 37, 10432 (1988).

${ }^{7}$ J. P. Pelz and R. H. Koch, J. Vac. Sci. Technol. B 9, 424 (1991).

${ }^{8}$ R. Martel, Ph. Avouris, and I.-W. Lyo, Science 272, 385 (1996).

${ }^{9}$ G. Dujardin, A. Mayne, G. Comtet, L. Hellner, M. Jamet, E. Le Goff, and P. Millet, Phys. Rev. Lett. 76, 3782 (1996).

${ }^{10}$ I.-S. Hwang, R.-L. Lo, and T. T. Tsong, Phys. Rev. Lett. 78, 4797 (1997).

${ }^{11}$ K.-Y. Kim, T.-H. Shin, S.-J. Han, and H. Kang, Phys. Rev. Lett. 82, 1329 (1999).

${ }^{12}$ K. Sakamoto, S. Doi, Y. Ushimi, K. Ohno, H. W. Yeom, T. Ohta, S. Suto, and W. Uchida, Phys. Rev. B 60, R8465 (1999).

${ }^{13}$ F. Matsui, H. W. Yeom, K. Amemiya, K. Tono, and T. Ohta, Phys. Rev. Lett. 85, 630 (2000).

${ }^{14}$ T. Jensen, L.-B. Tækker, C. Gundlach, F. K. Dam, P. Morgen, S. V. Hoffman, Z. Li, and K. Pedersen, Phys. Rev. B 64, 045304 (2001).

${ }^{15}$ G. Comtet, L. Hellner, G. Dujardin, and K. Bobrov, Phys. Rev. B 65, 035315 (2002).

${ }^{16}$ K. Sakamoto, F. Matsui, M. Hirano, H. W. Yeom, H. M. Zhang, and R. I. G. Uhrberg, Phys. Rev. B 65, 201309 (2002).

${ }^{17}$ H. Okuyama, T. Miki, T. Aruga, and M. Nishijima, Jpn. J. Appl. Phys., Part 2 41, L1419 (2002).

${ }^{18}$ K. Sakamoto, H. M. Zhang, and R. I. G. Uhrberg, Phys. Rev. B 68, 075302 (2003).

${ }^{19}$ A. J. Mayne, F. Rose, G. Comtet, L. Hellner, and G. Dujardin, Surf. Sci. 528, 132 (2003).

${ }^{20}$ H. Okuyama, T. Aruga, and M. Nishijima, Phys. Rev. Lett. 91, 256102 (2003).

${ }^{21}$ K. Sakamoto, H. M. Zhang, and R. I. G. Uhrberg, Phys. Rev. B 70, 035301 (2004).

${ }^{22}$ Y. Konishi, S. Yoshida, Y. Sainoo, O. Takeuchi, and H. Shigekawa, Phys. Rev. B 70, 165302 (2004).

${ }^{23}$ B. Schubert, Ph. Avouris, and R. Hoffmann, J. Chem. Phys. 98, 7593 (1993); J. Chem. Phys. 98, 7606 (1993).

${ }^{24}$ H. Kageshima, Y. Ono, M. Tabe, and T. Ohno, Jpn. J. Appl. Phys., Part 1 33, 4070 (1994).

${ }^{25}$ S.-H. Lee and M.-H. Kang, Phys. Rev. Lett. 82, 968 (1999).

${ }^{26}$ S.-H. Lee and M.-H. Kang, Phys. Rev. B 61, 8250 (2000).

${ }^{27}$ T. Hoshino and Y. Nishioka, Phys. Rev. B 61, 4705 (2000).

${ }^{28}$ M.-H. Tsai, Y.-H. Tang, I.-S. Hwang, and T. T. Tsong, Phys. Rev. B 66, 241304 (2002).

${ }^{29}$ H. W. Yeom, Phys. Rev. B 66, 157301 (2002).

${ }^{30}$ H. Ibach and D. L. Mills, Electron Energy-Loss Specroscopy and Surface Vibrations (Academic, New York, 1982). 